\title{
Africa regional sexual and gender-based violence network consultation: Technical exchange and planning meeting
}

Population Council

Follow this and additional works at: https://knowledgecommons.popcouncil.org/departments_sbsr-rh

Part of the Demography, Population, and Ecology Commons, Domestic and Intimate Partner Violence Commons, Family, Life Course, and Society Commons, Gender and Sexuality Commons, International Public Health Commons, Medicine and Health Commons, and the Women's Health Commons How does access to this work benefit you? Let us know!

\section{Recommended Citation}

"Africa regional sexual and gender-based violence network consultation: Technical exchange and planning meeting." Nairobi: Population Council, 2008. 


\title{
Africa Regional Sexual and Gender-Based Violence Network Consultation: Technical Exchange and Planning Meeting
}

\author{
Meeting Report
}

Roode Vallei Lodge, Pretoria, South Africa $5^{\text {th }}-7^{\text {th }}$ March, 2008 


\section{Executive Summary}

In March 2008, the Population Council brought together members of the African regional network on Sexual and Gender Based Violence (SGBV) for a South-South technical exchange meeting. Participants included partners who are currently implementing SGBV projects supported by the Swedish-Norwegian HIV \& AIDS Team in Kenya, Zambia, South Africa, Ethiopia, Malawi, Zimbabwe, Senegal; and a set of new partners chosen to implement PEPFAR's Initiative on SGBV in Rwanda, Uganda and South Africa. A total of 45 participants from these 9 African countries met for 3 days to discuss experiences and develop linkages for implementing SGBV activities.

The objectives of the meeting were to identify best practices from existing programs, provide an evidence-base for new programming, and develop mechanisms for South-South technical assistance. The meeting was widely recognized as enabling an active, informative and energizing dialogue on a wide range of SGBV issues. As summarized by one participant, the event was "wonderful, informative and interesting...we benefitted so much!"

As detailed in this report, discussions covered the breadth of medical, legal and psychosocial issues associated with SGBV prevention and response activities. Based on their experiences, participants identified the following cross-cutting set of lessons learned:

- Protocols and guidance documents are essential for ensuring comprehensive, quality response at all levels.

- Enabling access and utilization of the full range of medical services remains a core challenge of SGBV programs.

- Psychosocial care for survivors is underexplored.

- Although children represent a significant proportion of SGBV survivors, their special needs are not routinely or adequately addressed.

- Community awareness and prevention activities are increasingly identified as a necessary component of SGBV programming.

- Implementation can be fostered by the development and exchange of quality SGBV programming tools, including materials for training, awareness creation, data collection and surveys.

The workshop also provided participants with an opportunity to plan technical exchange visits, and to begin developing implementation plans for PEPFAR partners' activities. At the meeting's conclusion, participants requested that the Council continue network-building activities by:

1. Identifying and documenting the best practices emerging within the network;

2. Continuing to keep the network alive by maintaining a current, accessible database of SGBV resources available within the network and the region;

3. Facilitating technical exchange visits among partners;

4. Developing a set of common indicators with which to evaluate the success of SGBV programs in Africa;

5. Employ lessons learned for advocacy at national and regional levels;

6. Providing on-going technical support to PEPFAR partners. 


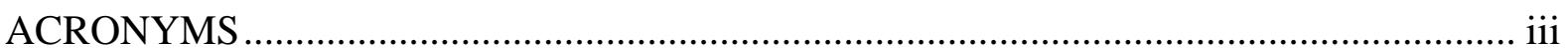

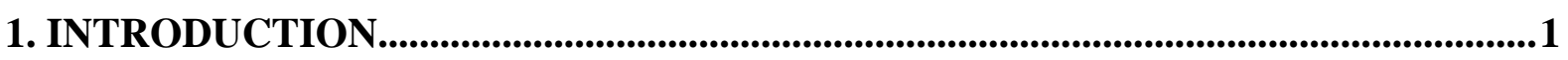

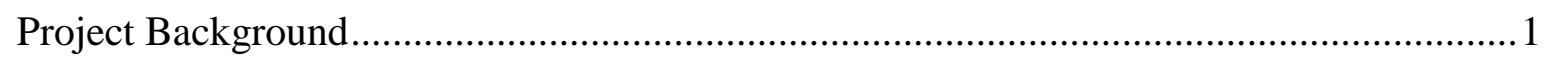

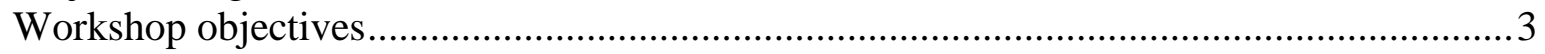

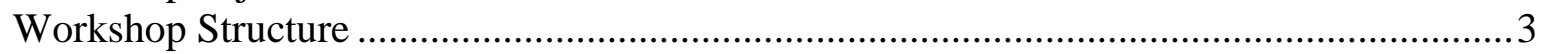

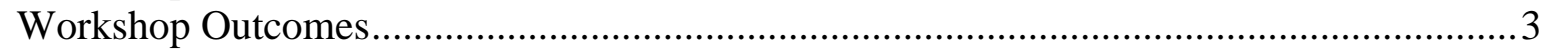

2. WORKSHOP SESSIONS DAY 1: $5^{\text {TH }}$ MARCH 2008 ..................................................6

Official Opening Remarks ............................................................................................. 6

Overview of the Swedish- Norwegian HIV \& AIDS Team for Africa's SGBV Initiative ...6

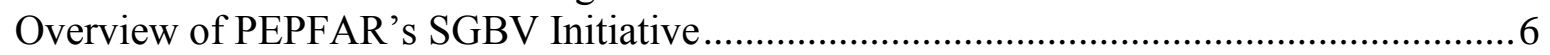

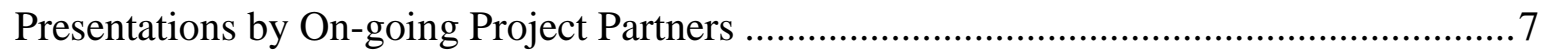

Identification of South-South Technical Assistance Opportunities ........................................ 10

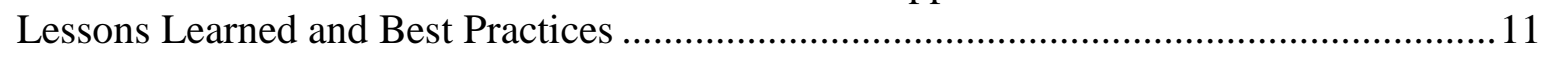

3. WORKSHOP SESSIONS DAY 2: $6^{\text {TH }}$ MARCH 2006 .................................................... 15

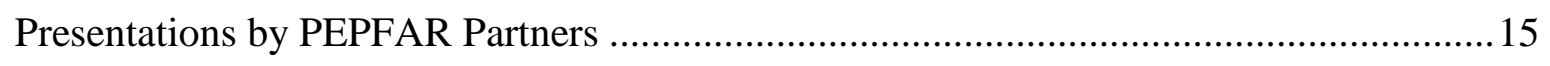

4. WORKSHOP SESSIONS DAY 3: MARCH $7^{\mathrm{TH}}$ 2008 ................................................ 19

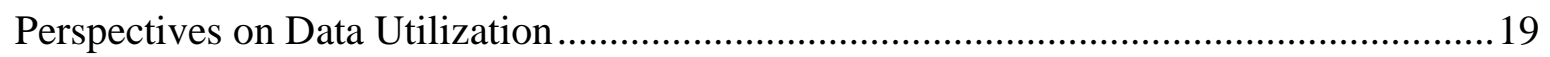

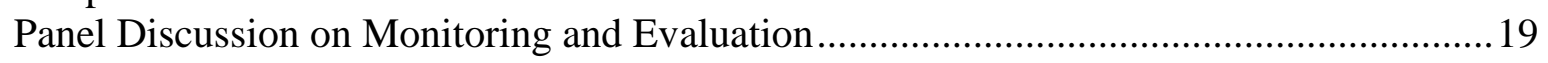

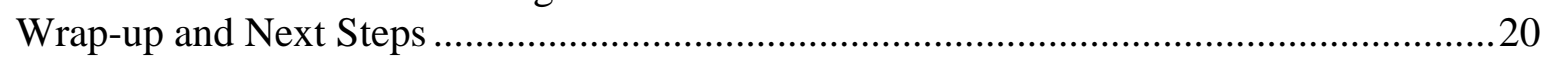

APPENDIX 1: LIST OF PARTICIPANTS ...............................................................21 


\section{ACRONYMS}

$\begin{array}{ll}\text { ART } & \text { Anti-Retroviral Therapy } \\ \text { ARV } & \text { Anti-Retro Viral } \\ \text { CAVs } & \text { Committees Against Violence } \\ \text { CBD } & \text { Community Based Distributor } \\ \text { CJS } & \text { Criminal Justice System } \\ \text { DRH } & \text { Department of Reproductive Health } \\ \text { DV } & \text { Domestic Violence } \\ \text { EANASO } & \text { East African Network of AIDS Services Organization } \\ \text { EBD } & \text { Employer Based Distribution } \\ \text { EC } & \text { Emergency Contraception } \\ \text { ESA } & \text { East and Southern Africa } \\ \text { FPC } & \text { First Point of Contact } \\ \text { FVSA } & \text { Family Violence and Sexual Abuse } \\ \text { GTWG } & \text { Gender Technical Working Group } \\ \text { IEC } & \text { Information Communication Materials } \\ \text { MOH } & \text { Ministry of Health } \\ \text { PEP } & \text { Post Exposure Prophylaxis } \\ \text { PEPFAR } & \text { President's Emergency Plan for Aids Relief } \\ \text { PRC } & \text { Post Rape Care } \\ \text { SANASO } & \text { South African Network of AIDS Services Organization } \\ \text { SAPS } & \text { South Africa Police Services } \\ \text { S-N Team } & \text { Swedish- Norwegian Regional HIV and AIDS Team for Africa } \\ \text { SGBV } & \text { Sexual and Gender Based Violence } \\ \text { SOCA } & \text { Sexual Offences and Community Affairs } \\ \text { SSO } & \text { Survivor Support Officers } \\ \text { SV } & \text { Sexual Violence } \\ \text { TA } & \text { Technical Assistance } \\ \text { TVEP } & \text { Thohoyandou Victim Empowerment Program } \\ \text { USAID } & \text { United States Agency for International Development } \\ \text { VEP } & \text { Victim Empowerment Program } \\ \text { VSU } & \text { Victim Support Unit } \\ \text { WHO } & \text { World Health Organization } \\ & \end{array}$




\section{Introduction}

\section{Project Background}

In response to the growing awareness of the links between sexual and gender-based violence (SGBV), health, human rights and national development in East and Southern Africa, the Population Council with support from the Swedish- Norwegian Regional HIV and AIDS Team for Africa (S-N Team) initiated a multi-country SGBV network in 2006. This network includes eight partners in seven African countries: Kenya, South Africa, Zambia, Malawi, Zimbabwe, Senegal and Ethiopia. These partners are simultaneously implementing SGBV projects that seek to address the determinants and consequences of SGBV in an integrated and comprehensive manner and to strengthen national programmes to better meet the medical, psychological and justice needs of survivors of sexual and domestic violence and to enhance strategies for its prevention.

Lessons learned from these experiences are being systematically documented and synthesized to offer a policy framework and implementation guidelines that will be relevant for others seeking to strengthen programmes throughout the region. These lessons and guidelines will be widely shared with other regional and international networks, organizations and governments that would benefit from such information projects.

In 2008, ten PEPFAR implementing partners were added to the network as part of the PEPFAR Gender Technical Working Group's (GTWG) Initiative on Sexual and Genderbased Violence. As part of this Initiative, the Council will facilitate South-South technical exchanges between network members to support PEPFAR SGBV projects in Uganda, Rwanda and South Africa. Implemented in conjunction with the USAID-funded Health Policy Initiative (HPI) implemented by Constella Futures, it is intended to strengthen comprehensive responses to SGBV, with an emphasis on community linkages and medical management including provision of post-exposure prophylaxis for HIV (PEP). It will also work to develop a set of core indicators and monitoring and evaluation approaches for SGBV projects, intended to serve as a guideline for measuring the effectiveness of SGBV projects across Africa.

This meeting brought together partners from both projects, and a total of 45 participants from nine African countries, to share experiences and develop linkages for implementing SGBV activities (see appendix 1 for a list of participants). Table 1 summarizes these projects. 
Table 1: The African Regional SGBV Network

\begin{tabular}{|c|c|c|}
\hline Countries & Implementing partners & Project description \\
\hline Zambia & $\begin{array}{l}\text { Zambia Ministry of Health, Zambia } \\
\text { Police Service }\end{array}$ & $\begin{array}{l}\text { Developing and testing protocols for } \\
\text { comprehensive care in existing health } \\
\text { care and police settings }\end{array}$ \\
\hline \multirow{3}{*}{ South Africa } & $\begin{array}{l}\text { Tshwaranang Legal Advocacy } \\
\text { Centre }\end{array}$ & $\begin{array}{l}\text { Introducing and strengthening the legal } \\
\text { and mental health components of an } \\
\text { integrated model for post-rape care and } \\
\text { HIV PEP }\end{array}$ \\
\hline & $\begin{array}{l}\text { Thohoyandou Victim Empowerment } \\
\text { Program }\end{array}$ & $\begin{array}{l}\text { Reducing the incidence and impact of } \\
\text { SGBV through sustainable } \\
\text { implementation of a multi-sectoral } \\
\text { prevention and support strategy }\end{array}$ \\
\hline & $\begin{array}{l}\text { PEPFAR Partners: RTI } \\
\text { International, South African Defense } \\
\text { Force, Medical Research Council }\end{array}$ & $\begin{array}{l}\text { Strengthening the capacity of local } \\
\text { partners and institutions to deliver } \\
\text { quality healthcare services including } \\
\text { PEP to survivors of sexual violence }\end{array}$ \\
\hline Kenya & Liverpool VCT, Care and Treatment & $\begin{array}{l}\text { Development of standards for a } \\
\text { 'custody of evidence' chain for post- } \\
\text { rape services }\end{array}$ \\
\hline Zimbabwe & $\begin{array}{l}\text { Musasa Project, Zimbabwe National } \\
\text { Family Planning Association }\end{array}$ & $\begin{array}{l}\text { Building capacity of community based } \\
\text { distributors to deliver SGBV services }\end{array}$ \\
\hline Malawi & Human Resource Centre & $\begin{array}{l}\text { Developing a national network of key } \\
\text { stakeholders, and building cross- } \\
\text { sectoral capacity }\end{array}$ \\
\hline Ethiopia & $\begin{array}{l}\text { Ethiopian Society of Obstetricians } \\
\text { and Gynaecologists }\end{array}$ & $\begin{array}{l}\text { Strengthening model clinic services } \\
\text { and nationalizing guidelines on } \\
\text { comprehensive management for } \\
\text { survivors of sexual assault }\end{array}$ \\
\hline Senegal & $\begin{array}{l}\text { Centre de Formulation et de } \\
\text { Recherche en Sante de la } \\
\text { Reproduction }\end{array}$ & $\begin{array}{l}\text { Documenting the characteristics of } \\
\text { sexual and domestic violence survivors } \\
\text { in Dakar health facilities }\end{array}$ \\
\hline Rwanda & $\begin{array}{l}\text { PEPFAR Partners: Drew Cares } \\
\text { International (DCI) and the Rwanda } \\
\text { Defense Force (RDF); IntraHealth; } \\
\text { The International Center for AIDS } \\
\text { Care and Treatment Programs; } \\
\text { AIDS Relief }\end{array}$ & $\begin{array}{l}\text { Strengthening the capacity of local } \\
\text { partners and institutions to deliver } \\
\text { quality healthcare services including } \\
\text { PEP to survivors of sexual violence }\end{array}$ \\
\hline Uganda & $\begin{array}{l}\text { PEPFAR Partners: Northern Uganda } \\
\text { Malaria, AIDS Tuberculosis } \\
\text { Program; Uganda People's Defense } \\
\text { Force; Makerere University Joint } \\
\text { AIDS Program }\end{array}$ & $\begin{array}{l}\text { Strengthening the capacity of local } \\
\text { partners and institutions to deliver } \\
\text { quality healthcare services including } \\
\text { PEP to survivors of sexual violence }\end{array}$ \\
\hline
\end{tabular}




\section{Meeting objectives}

For partners supported by the S-N Team, this meeting served as an opportunity to review progress at the mid-term of project implementation. The workshop also introduced the new PEPFAR partners from Rwanda, Uganda and South Africa, and provided the opportunity to create and strengthen linkages among all partners, by allowing participants to exchange information, resources and technical assistance.

Specific objectives were to:

- Review progress in implementing SGBV projects under the Council's multi-country SGBV project;

- Identify and share lessons learned and materials developed to date;

- Introduce the PEPFAR SGBV Initiative and implementing partners;

- Identify technical assistance (TA) needs of PEPFAR Initiative partners and develop plans for TA exchange with the Council partners and others;

- Develop work plans for PEPFAR partners in Rwanda, Uganda and South Africa;

- Discuss monitoring and evaluation approaches for both sets of partners.

\section{Meeting Structure}

Held over three days, the event was comprised of three distinct components. The first included presentations on the projects implemented by the S-N Team-supported partners and the projects envisioned by the PEPFAR partners. A second set of sessions included planning and identification of TA needs, and the third component addressed monitoring strategies and the development of a common evaluation framework for all projects. All sessions were highly interactive and afforded participants an opportunity to interact and share their views on experiences captured in the different presentations (see appendix 2 for the agenda).

\section{Meeting Outcomes}

The meeting was widely recognized as enabling an active, informative and energizing dialogue on a wide range of SGBV programming issues. Participants noted that, in many countries, SGBV programs tend to work in isolation, with few colleagues and limited institutional support. This event provided a much-needed forum for technical exchange, allowing partners to share experiences, challenges, and programming strategies. It also confirmed the viability of the South-South technical assistance model upon

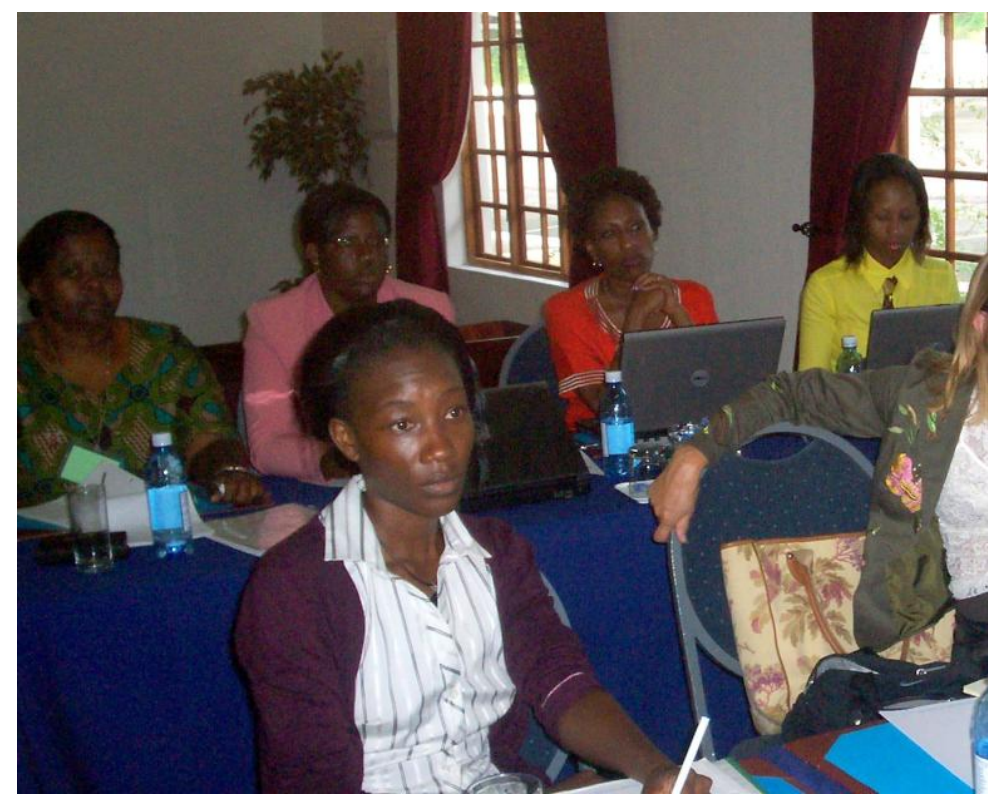
which the Council's regional SGBV network is based, and highlighted the key role it can play 
in transmitting and creating knowledge on SGBV programming. As summarized by one participant, the meeting was "wonderful, informative and interesting...we benefited so much!"

As detailed in this report, discussions covered the breadth of medical, legal and psychosocial issues associated with SGBV prevention and response activities. A set of key cross-cutting themes emerged:

- Protocols and guidance documents are essential. Participants agreed that a critical component of effective, comprehensive programming was clear guidance at every level. Currently, however, few national governments, public health or legal systems have developed such guidelines. In countries where they do exist, such as South Africa, implementation remains a challenge. All of the projects supported by the network are in some way working to create or strengthen the policy framework for SGBV programming in their countries. In Zambia, for example, the Council is collaborating with government bodies to develop national protocols for medical management and police responses to SGBV; in Kenya, Liverpool VCT is developing an evidence base to inform national procedures on forensic evidence collection and utilization.

- Enabling access and utilization of the full range of medical services remains a core challenge of SGBV programs. Survivors do not necessarily seek medical care first. Experiences from across the network indicate that police are most often the first point of contact, and referrals to health facilities are undermined by limited knowledge of such services, both on the part of police and survivors. Among survivors with limited economic resources, transportation costs serve as a further disincentive to visiting a second point of contact. South Africa's Thohoyandou Victim Empowerment Program (TVEP) program and Thuthuzela Care Centers (TCC) offer innovative models for minimizing the attrition between points of contact, utilizing different strategies for creating linkages between police and health services.

Once at health facilities, quality of care can be compromised by low provider awareness of necessary procedures and treatments, including the provision of HIV post-exposure prophylaxis (PEP), numerous referrals across hospital departments, and incomplete collection of forensic evidence. Network partners are testing different approaches to overcoming these barriers, ranging from the Tshwaranang Legal Advocacy Centre's (TLAC) model of integrated services within hospitals to the Ethiopian Society of Obstetricians and Gynecologists' (ESOG) one-stop-shops for post-rape care.

- Psychosocial care for survivors is underexplored. While much progress has been made in the areas of medical management and legal responses, very little is known about addressing the short and long-term psychosocial needs of survivors. Participants consistently identified this as an area for improvement in their own programs, noting the constraints posed by a limited evidence and experience base.

- Special needs of child survivors need to be better addressed. Nearly all of the partners reported that children constitute a significant proportion of their SGBV clients. Nonetheless, few programs have specific policies and procedures for the care and treatment of young survivors, and often tend to be oriented to the needs of adult 
women. Psychosocial care is one key area where disaggregated programmatic approaches are critical. CMIC is responding to these gaps by including clear guidance on child survivors in Zambia's medical management and police protocols. More research, however, is needed to develop an evidence base on successful child-focused SGBV services in Africa.

- Community awareness and prevention activities are an emerging area of concern. To date, partners' programs have largely focused on developing the capacity of health, police or legal institutions. As these efforts progress, participants recognize a need to place more emphasis on creating demand for such services by reaching out to communities. The PEPFAR projects are being specifically designed with this concern in mind, receiving support from HPI to undertake participatory planning and sensitization activities. Partners also strongly argued for an increased emphasis on prevention activities as a necessary element in achieving the ultimate goal of reducing the overall number of SGBV cases.

- Quality SGBV programming tools needed. Participants consistently expressed the need for validated, Africa-relevant training curricula, monitoring and evaluation (M\&E) tools. TLAC, TVEP and the Council's project in Zambia shared selected tools during the workshop, and requested that the network facilitate wider exchange among the partners. It is expected that this collaboration will yield a set of refined tools to support future programming efforts. 


\section{Meeting Sessions Day 1: $5^{\text {th }}$ March 2008}

\section{Official Opening Remarks}

Dr. Ian Askew (Population Council, Nairobi) officially opened the meeting. He started by welcoming participants to the meeting and acknowledging the presence of S-N Team representative and PEPRAR GTWG members in the meeting. He commended the S-N Team for their continued support and lauded PEPFAR for piloting projects to develop comprehensive responses to GBV in Uganda, Rwanda and South Africa.

He noted that recent work by the Council indicated that adequate information on GBV is lacking in the region and what exists is not shared among partners in a coordinated way. To begin responding to this need, the Population Council had consolidated a resource base of materials on research and data collection tools, IEC, protocols and guidelines on SGBV available in the region. This was made available to participants in CD format.

\section{Overview of the Swedish- Norwegian HIV \& AIDS Team for Africa's SGBV Initiative}

Dr. Peter Iveroth (S-N Team) congratulated partners for the commendable work they had done to date. He noted that there was considerable growth in the project and that the S-N Team was impressed by the work being pioneered by the network. Also he acknowledged and appreciated was the addition of 10 new PEPFAR partners to the network. He noted that working together would facilitate linkages with regional bodies and initiatives such as Southern African Network of AIDS Service Organizations (SANASO) and that East African Network of AIDS Services Organization (EANASO).

\section{Overview of PEPFAR's SGBV Initiative}

Ms. Susan Settergren (GTWG Co-chair, CDC) and Ms. Heidi Mihm (GTWG, USAID) gave an overview of the PEPFAR SGBV Initiative. It grew out of a 2006 consultation that looked at ways to strategically address gender across PEPFAR. SGBV, in addition to male norms and vulnerable girls, was a key priority area identified by this exercise.

The goal of the SGBV Initiative is to strengthen comprehensive treatment services for survivors of sexual violence. This includes strengthening delivery of clinical care including HIV post-exposure prophylaxis (PEP), strengthening linkages between clinical services and other sexual violence services, and strengthening community roles to improve access to and quality of services. Pilot models will be developed and tested in three countries, Uganda, Rwanda and South Africa, building upon existing services through provision of PEP, and improving linkages with communities to increase access to services. The initiative includes an evaluation of uptake and quality of services at pilot sites in order to inform program strengthening and scale-up within these countries as well as in other counties through out Africa. To date, implementing partners in Uganda, Rwanda, and South Africa have been identified and, are developing a framework for evaluating the utilization of services. Lessons from the project will provide a resource base for the partnership and will be shared widely in the network and across PEPFAR. Implementing partners have been identified in Uganda, Rwanda and South Africa and work is on-going to develop work and evaluation plans in these countries. 


\section{Presentations by On-going Project Partners}

Presentations afforded participants the opportunity to review the progress of the on-going projects funded by the S-N Team. They highlighted achievements and challenges, lessons learnt, TA needs and areas in which they could assist PEPFAR and SIDA partners. Partners reviewed the four major programs under the initiative, implemented in South Africa, Kenya and Zambia; as well as the projects receiving start-up seed grants, in Ethiopia, Malawi, Senegal and Zimbabwe. 


\section{Thohoyandou Victim Empowerment Program (TVEP)}

Ms Fiona Nicholson (Executive Director) noted that TVEP was launched in 2002 and is located in South Africa's Limpopo Province. It operates one-stop shop SGBV centers in two public hospitals, and provides community-based services in rural Sibasa. This model employs a "buddy system" to support survivors, in which a volunteer Social Support Officer (SSO) is assigned to each survivor as they enter the facility. The SSO then accompanies the survivor throughout all hospital and police processes, ensuring that services are properly rendered, and then continues follow-up support once the survivor returns to the community. This system has been used to successfully monitor PEP adherence, something that many SGBV programs have struggled with. The current project works to strengthen and expand these multi-sectoral prevention and support strategies offered at the centers. Special emphasis is given to the needs of children, who constitute $60 \%$ of all cases received.

Challenges faced during implementation include a lack of government support and funding, and integration with parallel TCC system currently under rapid expansion. The SSOs are also often marginalized by providers, especially police, who tend to regard them as unnecessarily complicating the process.

\section{Tshwaranang Legal Advocacy Centre (TLAC)}

Ms Liesl Gerntholz (Executive Director) provided an overview of the phase II Refentse project, which works to integrate legal services into the domestic and sexual violence services provided in one rural South African public hospital under phase I of the project. Initially, the Refentse project developed a "nurse-driven model" of sexual assault care, where nurses were trained to take client histories, administer PEP \& STI prophylaxis, and refer clients for legal advice and counseling. Under phase II, TLAC has stationed a paralegal at the hospital in an attempt to increase access to justice. If clients wish to pursue litigation, the paralegal assists them in filing a case at the police station, which is also situated within the hospital premises.

TLAC has found that a major challenge to prosecuting SGBV cases is the loss of documentation and files at the hospitals. Services are also over-stretched and therefore unable to cater for all clients' needs. TLAC has recently conducted a study to establish the needs of sexual assault survivors, which indicates that the majority do not give legal services a priority. Instead, they prioritize access to medical and psycho-social care. This issue is currently being exploring further.

\section{Liverpool Voluntary Counseling and Testing and Care (LVCT)}

Ms Caroline Ajema (Research Coordinator) presented on a study aimed at developing a minimum standard for collecting and maintaining a forensic evidence chain in the public sector. This study is being implemented in two Kenyan districts, Rachuonyo and Kitui, located in Western \& Eastern Kenya respectively. It seeks to examine factors that effect collection, storage and transportation. In implementing this study, LVCT has enhanced its links with the police, community and Kenya's government chemist. Main challenges presented included lack of clarity among survivors and providers on the most appropriate first points of contact, and related difficulties in terms of record collection. Surveyed police and health workers were also found to be frequently unaware of what legally constitutes rape or defilement. Overall, Liverpool's work in Kenya in focused on developing the evidence base necessary for improving SGBV policy and programming. 


\section{The Copperbelt Model for Comprehensive Care (CIMC)}

Ms Mary Zama (Project Manager) provided an overview of the CIMC project, implemented by the Population Council and the Zambian Ministries of Health and Home Affairs in the country's Copperbelt Province. Work began in 2005, as a study examining the feasibility of providing EC to SGBV survivors through specially-trained police officers. In 2007, it joined the SGBV network as a program to test comprehensive strategies for SGBV care in public sector hospitals and police stations.

To date, the project's major achievement is the development of two protocols, on medical management and police response, which are currently being reviewed for national adaptation. These protocols, drafted initially to guide program implementation, were immediately recognized by the two partner Ministries as valuable as central-level guidance. Prior to project implementation, therefore, the project was asked to assist the government in finalizing these documents. A key lesson learned through this process is the time required for stakeholder deliberation and consensus-building. Currently, these protocols are under final review, and are expected to be approved by the end of the current project.

In anticipation of the project kick-off, in September 2007, a baseline survey of health care providers and police officers was conducted in the intended intervention sites. Key findings demonstrate that provider attitudes present significant barriers to providing effective SGBV services:

- Only one-third (33\%) of health care providers believed that a rape survivor has "serious medical problems";

- The majority of police $(80 \%)$ agreed that "some women lie about rape to punish men."

In light of these and other findings, the intervention phase of the project will focus on developing a training curriculum to address these misconceptions.

\section{The Ethiopian Society of Gynecologists and Obstetrics (ESOG)}

Dr. Eskinder Kabede (Project Manager) gave an overview of the seed-grant project jointly implemented by ESOG and the Gandhi Memorial Hospital in Addis Ababa, Ethiopia. It seeks to institutionalize the model sexual assault clinic located at the hospital, with a view to nationalizing its medical management guidelines and training providers nationwide. He informed participants that so far hospital, police and judicial staff have been trained on a comprehensive response on sexual violence. A key success noted is that the model sexual assault clinic has been successfully integrated into other RH services at the hospital. Management of rape at the facility has also been effectively integrated into other services such as VCT, PMTCT, ART, safe abortion care, post abortion FP \& others. Draft management guidelines have been produced and a strategy has been put in place to nationalize them.

\section{Malawi Police Victim Support Unit (VSU) and Department of Reproductive Health (DRH)}

Dr. Emmy Mbale (Officer in Charge, DRH) presented on the seed-grant project in Malawi, which is working to create a functional and effective network of key SGBV stakeholders. Advocacy activities have included orienting traditional leaders, police, health, judiciary on best practices in responding to sexual violence, meetings with the District Assembly, and the 
engaging the media was to air sensitization programs on local radio stations. As a result of these efforts, SGBV has now become a topic for discussion at the district level; at the national level, the project has helped develop an active network to address SGBV policy issues. Overall, a key challenge noted was the lack of capacity and negative attitudes among health service providers. Major lessons emerging are that IEC materials are needed and that coordination of different service providers are crucial elements of comprehensive care and support.

\section{Centre de Formation et de Recherche en Sante de la Reproduction (CEFOREP)}

Dr. Thierno Dieng (Research Statistician) discussed the planned seed-grant activity in Dakar, Senegal, which is currently under ethical review. The proposed study will examine the frequency of SGBV cases reporting to selected facilities, client experiences with SGBV and the knowledge, attitudes and practices of health providers. Sites for the study have already been selected, although ethical review is pending due to the study's intention to interview some SGBV survivors.

\section{Musasa Project}

Ms. Linda Musiyiwa (Chairperson) presented an overview of the achievements accomplished by the seed grant project in Zimbabwe. In the past one year, the project has improved and strengthened capacity of community based distributors (CBD), to deal with issues related to gender based violence, HIV\& AIDS and human rights. Also their attitudes towards survivors of sexual violence have immensely improved and are now sensitive in their counseling and referral (to police and health facilities) roles. Field support visits conducted for CBDs have facilitated the process mainstreaming of SGBV issues into family and reproductive health services. The economic crisis in Zimbabwe particularly the operation dzikiza mutengo (cutting down of prices) led to reduced supplies of goods in the market. The result was that the project had money but there was nothing to spend it on. High inflation rates led to cost cutting measures such as reducing the number of training workshops and CBD receiving training.

\section{Identification of South-South Technical Assistance Opportunities}

To facilitate South-South technical exchange, at the end of each presentation partners were asked to highlight the TA they could offer and the TA they hoped to receive from the network. Most of these needs centered on the key thematic areas of medico-legal and psychosocial care and support of support of survivors. Table 2 summaries each partners' TA needs and requests. 
Table 2: Summary of South-South Technical Assistance Opportunities

\begin{tabular}{|c|c|c|c|}
\hline Countries & $\begin{array}{l}\text { Implementing } \\
\text { Partners }\end{array}$ & TA to Offer & TA Requested \\
\hline \multirow{2}{*}{$\begin{array}{l}\text { South } \\
\text { Africa }\end{array}$} & TVEP & $\begin{array}{l}\text { M\&E data collection systems } \\
\text { Monitoring PEP adherence } \\
\text { through SSO "buddies" }\end{array}$ & $\begin{array}{l}\text { Management and funding } \\
\text { sustainability }\end{array}$ \\
\hline & TLAC & $\begin{array}{l}\text { Provision of legal aid for } \\
\text { survivors of rape in resource } \\
\text { poor settings }\end{array}$ & $\begin{array}{l}\text { Integrating paralegal } \\
\text { services in health model for } \\
\text { rape survivors. }\end{array}$ \\
\hline Kenya & LVCT & $\begin{array}{l}\text { Development of protocols } \\
\text { and programs for post rape } \\
\text { care }\end{array}$ & $\begin{array}{l}\text { Strengthening and } \\
\text { improving M\&E system } \\
\text { Creating linkages with key } \\
\text { stakeholders. }\end{array}$ \\
\hline Zambia & CIMC & $\begin{array}{l}\text { Development of medical and } \\
\text { legal protocols } \\
\text { Provider attitudes surveys }\end{array}$ & Community mobilization \\
\hline Ethiopia & ESOG & $\begin{array}{l}\text { Establishment of a model } \\
\text { clinic for PRC } \\
\text { Development of medical } \\
\text { management guidelines }\end{array}$ & $\begin{array}{l}\text { Information sharing and } \\
\text { exchange }\end{array}$ \\
\hline Malawi & VSU \& DRH & $\begin{array}{l}\text { Orientation of traditional } \\
\text { leaders, police, health, } \\
\text { judiciary }\end{array}$ & $\begin{array}{l}\text { Establishment of one-stop } \\
\text { centre } \\
\text { Establishing data systems } \\
\text { Capacity in forensic analysis }\end{array}$ \\
\hline Zimbabwe & Musasa project & $\begin{array}{l}\text { Integrating GBV into family } \\
\text { planning and reproductive } \\
\text { health issues }\end{array}$ & $\begin{array}{l}\text { Developing protocols on } \\
\text { GBV } \\
\text { Establishing M\&E systems }\end{array}$ \\
\hline Senegal & CEFOREP & Project under development & $\begin{array}{l}\text { Developing data collection } \\
\text { and analysis tools }\end{array}$ \\
\hline
\end{tabular}

\section{Lessons Learned and Best Practices}

Through plenary and thematic break-out sessions, a set of lessons learned and best practices were identified from partners' presentations. These were discussed in terms of the four key components of the comprehensive model.

\section{Medical management}

Overall, participants agreed that standardized, multi-sectoral frameworks, guidelines and sensitization tools were important for ensuring comprehensive care. Training and capacity 
building of service providers were also seen as necessary for overcoming management issues, gender inequity and provider attitudes.

The presentations identified several service delivery models for public sector medical services. In general, it was agreed that successful models were able to centralize care, either in a one-stop center or among a limited number of departments of one facility. Notable aspects of these models were:

- The Refentse project's nurse-driven approach, which demonstrated that nurses can provide quality SGBV services, including forensic evidence collection. This is an important finding for resource poor environments, where shortages of doctors often undermine medical responses to SGBV.

- The Kenyan Ministry of Health's (supported by LVCT) comprehensive approach to post-rape care in public facilities. With published guidelines for medical management, staff training on care, and specially-designed reporting forms, the Kenyan model was seen as an excellent example of providing integrated services within public health facilities.

- The one-stop trauma centers managed by TVEP were noted for their ability to provide 24-hour services, in recognition of the fact that all rapes do not occur during business hours.

- In general, participants observed that strategies for care and response need to be defined at national to local levels.

In terms of provider capacity and standards, lessons learned included:

- Police, who often serve as the survivor's first point of contact, benefit from training and sensitization on the medical necessity of care to promote referrals to the health facility.

- South Africa and Kenya have valuable guidelines for medical management that can be adopted by other countries. South Africa also has excellent STI prophylaxis guidelines.

- Counseling care is an important part of medical management, but psychosocial care is ongoing and needs to be covered in separate protocols and programming.

\section{Police and legal services}

Discussions highlighted the lack of evidence on medico-legal linkages in SGBV programming. Little is known about a survivor's motivation for legal redress or the number and nature of successful prosecutions; even less is known about successful strategies for rehabilitating perpetrators. Preliminary data from TLAC's study suggests that survivors prioritize police and legal services over health care, although their expectations for 'justice' differ widely. Participants agreed that more research and programming experience is needed in this area.

Forensic evidence collection was identified as one key area for addressing medico-legal linkages within existing programs. Current best practices were identified as: 
- CIMC's model for police involvement in care and support of survivors of rape and defilement. In this program, specialized Victim Support Unit (VSU) officers provide EC and active referrals for health care to survivors of sexual violence.

- TVEP's SSO "buddy system," where civil society volunteers work within the community to support survivors in their pursuit of legal redress.

Based on these experiences, participants noted that successful programs required:

- Clear protocols and forms that outline linkages police and health workers in regard to: 1) referrals between facilities; 2) forensic evidence collection procedures.

- Civil society involvement and/or engagement on the policy and program levels. Debate emerged, however, on the extent to which civil society should circumvent or support the public sector. While some civil society advocates contended that their impact was greater "outside the system," others argued that civil society should engage directly with the government to refine their programming strategies.

- Specialized Victim Support Units (VSU) within the police force, such as in Malawi and Zambia, which handle all SGBV cases.

\section{Working with communities}

It was widely recognized that intensive, multi-sectoral community involvement and advocacy is necessary to ensure the success of SGBV prevention and care activities. This point was underscored by an active debate among South African participants regarding the necessity of civil society participation in the planning and administration of the government TCC $^{1}$ centers. Partners critiqued the TCCs for their limited engagement with NGOs and the communities they serve, resulting in programs that ineffectively address the needs of SGBV survivors. TCC representatives accepted this critique, and invited these partners to provide such input at an upcoming national planning meeting.

\section{Stakeholder engagement}

Participants identified a set of measures for engaging civil society in SGBV programming as a priority issue:

- At the inception of all activities, conduct a needs assessment to find out avenues for greater community involvement and ownership of activities to encourage sustainability.

- Develop clear MOUs with different stakeholders to facilitate implementation of activities involving multiple stakeholders, and to assist in identifying their roles in fighting against SGBV.

- Mobilize community support of SGBV projects, which is important for advocacy at both the national and local levels.

- Design and undertake M\&E activities in a participatory manner to increase program accountability at the community level.

- Disseminate information to community for work planning and validation of findings.

1 TTCs are "one-stop" centers that are designed to offer medico-legal and psycho-social support to survivors of sexual violence in South Africa 


\section{Psychosocial support}

Participants in this group argued that psychosocial management is a critical, but often neglected, component of SGBV response. Most frequently, it is subsumed into medical management, and treated as part of HIV counseling and testing procedures. They contended that it is important for all survivors to receive specialized, ongoing trauma counseling administered by trained counselors or psychologists. Evidence on the most appropriate and cost-effective strategies for providing counseling in the African context is severely lacking.

Recommendations for work in this area include:

- Expanded research on strategies for providing psychosocial support to SGBV survivors in resource-poor environments.

- Development of evidence-based protocols that address the specific, separate needs of children and adult SGBV survivors. 


\section{Workshop Sessions Day 2: $6^{\text {th }}$ March 2006}

On the second day, PEPFAR partners from Rwanda, Uganda and South Africa delivered presentations on projects to be implemented under the new SGBV Initiative. Unlike the projects outlined above, the PEPFAR activities were still in the planning stage. Presentations, therefore, highlighted priority areas for the intervention and provided a brief situation analysis of the intended project sites. Afternoon sessions allowed PEPFAR partners an opportunity to develop specific work plans, while S-N Team funded partners began planning South-South technical exchange activities.

\section{Presentations by PEPFAR Partners}

The International Center for AIDS Care and Treatment Programs (ICAP)/ Columbia University, Rwanda

Ms. Eugenine Ingabire (Adherence and Linkages Team Leader), described the planned project to increase PEP provision and adherence, and enhance linkages between health facilities and police. It will employ early detection mechanisms already successfully operating in their PMTCT program, placing priority on providing PEP and psychosocial support for survivors. The program also intends to focus on strengthening its M\&E systems and data collection capacities at the facility level. The project will be implemented at Muhima and Gisenyi hospitals, located in urban and peri-urban contexts respectively, which both currently provide PEP, medical care and psycho-social and support services. As figure 1 demonstrates, children constitute a significant proportion of survivors reporting to one selected study site, so project activities will need to be responsive to the special needs of children.

\section{Figure 1: Monthly SGBV Trends in Gisenyi Hospital, Rwanda} January-December 07

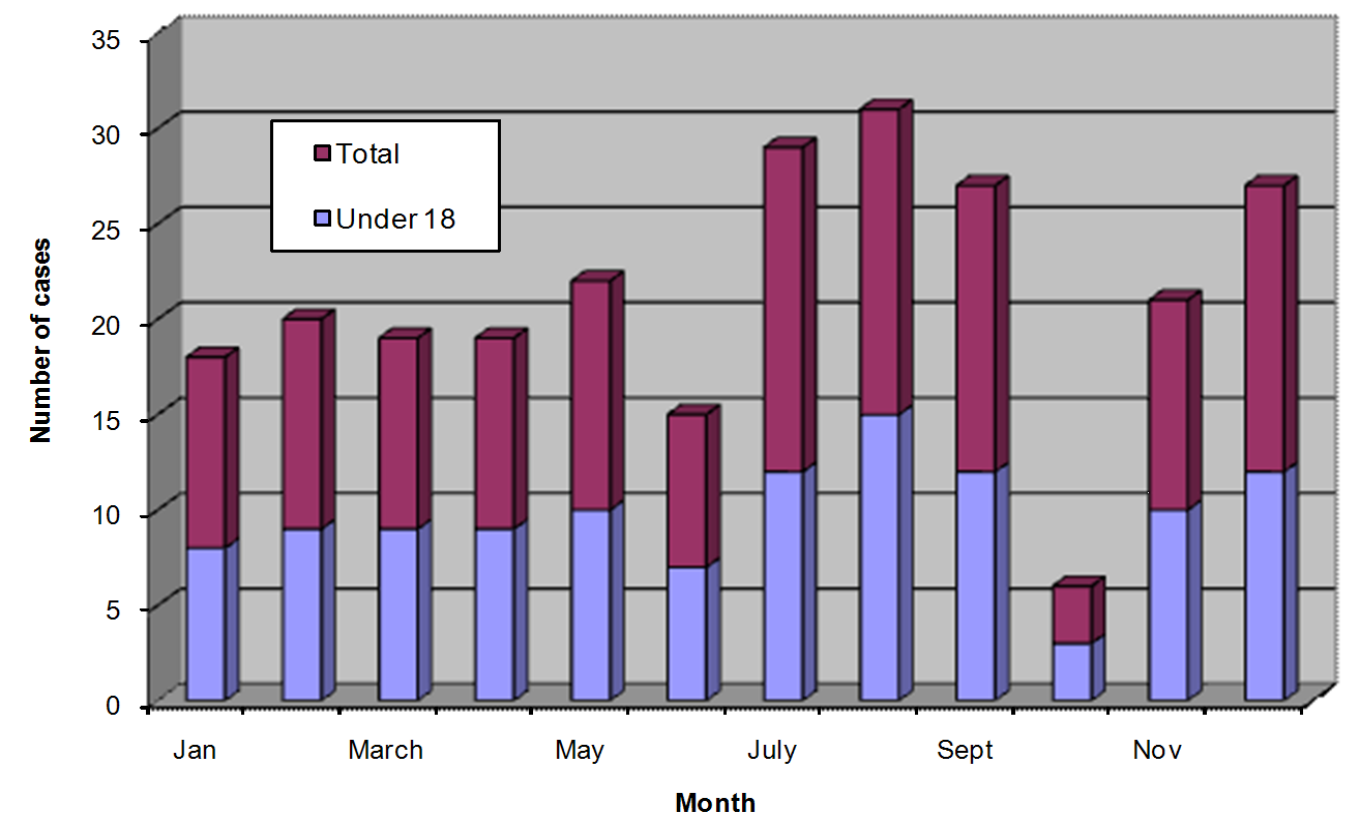


Mr. Dusabe-Mugabe (Psychosocial Service Director, DCI) gave an overview of the project that will be implemented at the Kanombe Military Hospital and Ngarama Military Health Center. The project will improve prevention, treatment and care to victims of sexual and gender based violence and improves linkages of different services offered. Cultural factors that inhibit reporting among the military and civilian populations in the catchment area were cited as a key challenge to successful implementation.

\section{AIDS Relief, Rwanda}

Ms. Marik Moen (HIV Nurseeducator) outlined the project, intended to increase provision of PEP to SGBV survivors and build the capacity of police and health staff to better respond to SGBV. It will do this by:

- Building awareness and capacity in whole community (from youth to elders) to facilitate early detection, appropriate management and prevention of SGBV;

- Orienting, train, mentor

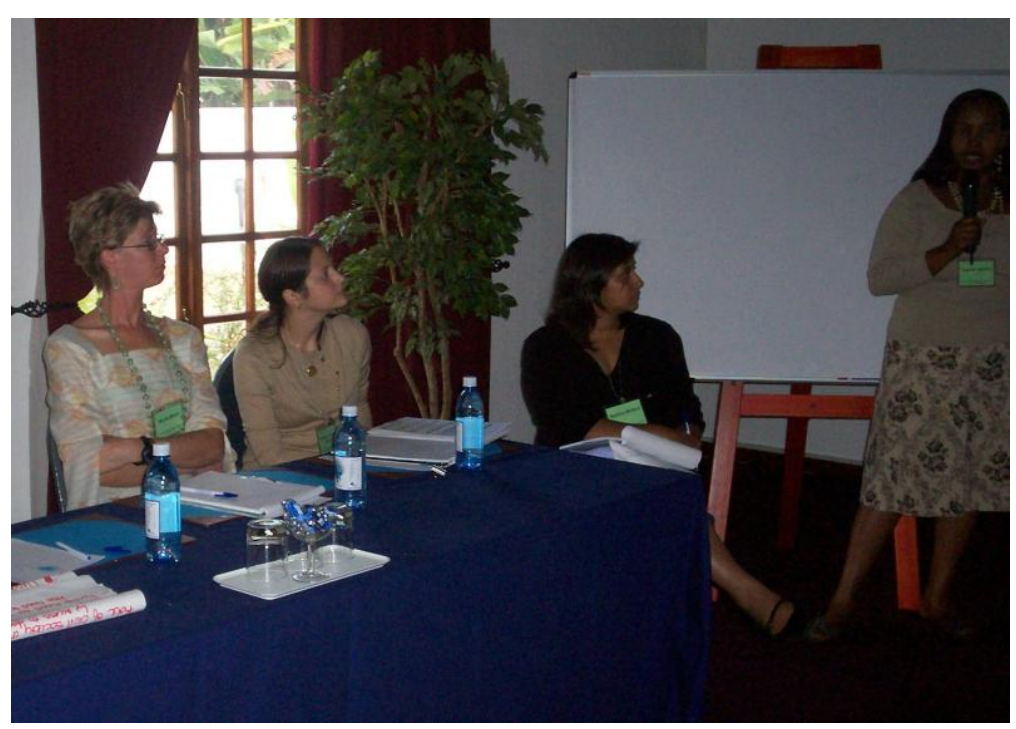
local health facility staff and non-health care partners in care and prevention;

- Establishing system at health centers to increase timely detection, prevention, care of GBV including use of community volunteers;

- Integrating services at healthcare facilities;

- Coordinating activities at community level for integrated care and prevention of GBV with local institutions (police, legal, health, psychosocial-economic affairs, schools, churches) and community volunteers.

The project will be implemented in Bungwe, Munyange and Kibogora Health Centers, which are all currently offering PEP services.

\section{IntraHealth HIV\&AIDS Clinical Services Program (HCSP), Rwanda}

Ms. Stephanie Marion-Landais (Program Officer) outlined the project which will strengthen clinical services for SGBV survivors, and foster linkages with the community and other service providers. It will introduce SGBV PEP services into four health facilities in Rwanda's Gicumbi District, and partner with the Community HIV/AIDS Mobilization Project (CHAMP) to create awareness of the services. Efforts will benefit from strong government support and buy-in to combat SGBV and the existence of Community-Provider Quality Assurance groups (PAQ) established under previous activities. The HCSP has also developed a wide network of official and NGO partners that can be drawn on to support implementation of SGBV activities. 
Dr. Edward Ssemafumu (Director, Clinical and Community Services) and Ms Sharon Ajedra Amacha (Manager, Prevention Services) described NUMAT's proposed efforts to strengthen the capacity of local partners and institutions to deliver quality healthcare services, including PEP, to survivors of sexual violence. Located in 9 districts of northern Uganda, the project will primarily serve the needs of conflict-affected communities, and will integrate SGBV services into existing HIV programs. Its activities will focus on six core areas: community awareness and sensitization, coordination of SGBV activities at district and sub-country levels, supporting healthcare, psychosocial support, community/policy training on legal issues, and security and protection services to prevent sexual assault.

\section{Mulago Mbarara Teaching Hospitals' Joint AIDS Program (MJAP), Uganda}

Dr. Doris Mwesegire (Assistant Programme Manager) presented the objectives of the project that will be implemented at a pilot site in Mulago hospital. The project aims to provide quality medical care for sexual abuse survivors, while forging linkages with the police, legal system and community for psychosocial care and follow-up. After one year of implementation, an evaluation will be conducted and scaled up to regional referral hospitals. Mulago hospital was selected as the intervention site because it is a national referral hospital with a police post on site and well trained staff. It also has an emergency unit for the sexually abused and PEP services available. The project will be implemented jointly with MJAP, the community and police.

\section{Uganda Peoples Defense Force (UPDF), Uganda}

Lt. Col. Dr. Stephen Kusasira (APC Coordinator) presented an overview of a project designed to strengthen the UPDF's institutional capacity to effectively deliver sustainable SBGV/HIV programs, including preventive measured, care and support. It will do this by conducting a baseline survey to assess the factors that contribute to SGBV, types and magnitude/extent of the problem, identify gaps/needs, and form the basis for M\&E activities. Tailored to the survey's findings, the intervention will entail social mobilization/ awarenessraising of the Ugandan Military community on SGBV and its relationship to HIV/AIDS. Social mobilization will be undertaken to raise awareness at community levels and build collaborative networks and partnerships with other players at the national level. Within the targeted hospitals, medical management services will be strengthened and SGBV will be integrated into routine training curriculum of health workers.

The project will be implemented in three infantry divisions operating in North and Northeastern parts of Uganda because the regions are prone to conflict, have high reported cases on SGBV and have high HIV prevalence rates. Resurgence of hostilities and conflict, difficulties in identifying victims, implementation and sustainability are among the notable challenges to implementation.

\section{RTI International, South Africa}

Ms Liz Randolph and Mr. Peter Vaz presented on their activities to support the South African government in its expansion of TCC facilities. They are currently working with the Sexual Offenses and Community Affairs Unit (SOCA) of the National Prosecuting Authority to strengthen the services offered at four existing TCCs. Based on a "gap analysis" conducted 
in 2007, SOCA has requested assistance in increasing the centers' compliance with the Department of Health's medical management guidelines; out of 10 TCCs reviewed, none ranked higher than the two sites with $75 \%$ percent compliance. Under the PEPFAR Initiative, this work will be expanded and focused to ensure access to a comprehensive package of services.

\section{Technical Assistance and Work Planning}

Following the presentations, the PEPFAR and S-N Team Funded partners divided into working groups. PEPFAR partners and country team members met with the GTWG representatives to begin planning specific activities under the Initiative. They were briefed on the TA available through Population Council and HPI, and discussed implementation concerns including timelines, budgets and reporting requirements. Each country group then met individually to discuss individual work plans, PEPFAR requirements and evaluation plans.

The S-N Team funded partners discussed objectives for the TA exchange visits and strategies for sharing IEC and material resources within the network. The Council was requested to plan exchange visits according to TA needs of individual partners (see table 2). 


\section{Workshop Sessions Day 3: March $7^{\text {th }} 2008$}

The final session of the workshop focused on issues concerning data collection and utilization, in response to needs identified by partners.

\section{Perspectives on Data Utilization}

Dr. Peter Iveroth (S-N Team) and Ms Susan Settergren (GTWG) discussed how data collected from the two initiatives would be used. Dr. Iveroth reiterated that the aim of this partnership is to build upon and strengthen existing SGBV initiatives addressing all aspects of care. S-N Team is especially interested in creating linkages within the region and to facilitate the development of comprehensive policies to respond to SGBV. He presented a matrix of cross cutting indicators, compiled from the partner's projects, which will be used to develop standards of measuring and evaluating SGBV work across the continent. The data produced through this work will be used to lobby and advocate for strengthening of existing policies on SGBV and the development of new ones.

Ms Settergren also noted that data from the PEPFAR Initiative will be collected in a systematic and in-depth way so that gains can be consolidated and provide an evidence base for scaling up pilot projects. Common indicators cutting across country projects will be shared to compare impact. This will be useful in furthering SGBV work by leveraging funding across PEPFAR and other funding agencies.

\section{Panel Discussion on Monitoring and Evaluation}

Representatives from TVEP, Liverpool VCT and CIMC formed a panel review best practices, challenges and strategies for M\&E. The following are the key points that emerged from the presentations and discussions:

Each program provided an overview of their data collection activities.

- In Zambia, CMIC has recently partnered with the police and Ministry of Health to conduct a baseline knowledge, attitudes and practices survey. To monitor service provision, the $\mathrm{MOH}$ has partnered with the police to record EC provision by police officers as part of $\mathrm{MOH}$ routine monitoring activities.

- In South Africa, TVEP SSOs ask survivors if they want ongoing support and monitoring, if they do, they are given a code for tracking follow-up. As a result, TVEP has a rich, largely untapped database of SGBV client records, including characteristics and care-seeking behaviors.

- In Kenya, LVCT staff work with the MOH to institutionalize M\&E within their post-rape care centers. They have developed a standardized reporting form that is used at health facilities, and is intended to aid in prosecution. Through this, LVCT has good records that give an indication of proportion of clients taking PEP, EC, testing, adherence and even how fast supplies are moving.

Discussions on M\&E revolved around ethics and confidentiality issues. The key concern for most participants was that if survivor records were accessible, confidentiality could potentially be breached, exposing survivors to further trauma. Specific responses from the panel were as follows: 
- TVEP requires all staff and volunteers to sign a confidentiality clause, and full data can only be accessed by the M\&E staff who are trained on confidentiality matters. Also, the personal interaction encouraged by the SSO "buddy system" instills trust and responsibility.

- In the Copperbelt, program staff are not able to directly access police or health facility client records. Data on EC use is kept in locked cabinets which can only be accessed by designated VSU officers. To facilitate data collection, the program has hired a VSU officer to collect information from police files and record it for use without names.

A key lesson highlighted by all participants is that data collection instruments must be developed in conjunction with program staff.

- If working with the government or existing programs, it is critical to ensure that reporting procedures do not significantly increase workloads. If a new data collection system is imposed on staff, it is likely that data quality will be compromised.

- Concerns were raised regarding the practice of paying staff to collect additional data, which was seen as unsustainable and undermining the work ethic of providers. One strategy for overcoming this was given by CMIC, which worked closely with the police and $\mathrm{MOH}$ to ensure that project reporting was prioritized by officials who then added it to the duties of their subordinates.

\section{Wrap-up and Next Steps}

The workshop ended with a brief wrap-up in which participants emphatically expressed how useful the workshop was for their work. Partners reiterated the desirability of a common framework or system to assist with collection of data and development of cross cutting indicators. They expressed the need for greater information sharing and TA exchanges among partners as a vehicle for strengthening the network.

Participants requested that the Council continue network-building activities by:

- Identifying and documenting the best practices emerging within the network;

- Continuing to keep the network alive by maintaining a current, accessible database of SGBV resources available within the network and the region;

- Facilitating technical exchanges among partners;

- Developing a set of common indicators with which to evaluate the success of SGBV programs in Africa;

- Providing technical support to PEPFAR partners. 
Appendix 1: List of Participants

\begin{tabular}{|c|c|c|}
\hline Country & Participant & Organization \\
\hline \multirow{2}{*}{ Ethiopia } & Asheber Gaym & ESOG \\
\hline & Eskinder Kebede & ESOG \\
\hline \multirow{3}{*}{ Kenya } & Margaret Meme & Ministry of Health \\
\hline & Hadley Muchela & LVCT \\
\hline & Carol Ajema & LVCT \\
\hline \multirow{2}{*}{ Malawi } & Patricia Msango & Malawi Police \\
\hline & Emmi Mbale & Malawi MOH \\
\hline \multirow{7}{*}{ Rwanda } & Josephine Mukamuganga & AIDS RELIEF \\
\hline & Marik Moen & AIDS RELIEF \\
\hline & Eugenie Ingabire & ICAP/ Columbia University \\
\hline & Dubase Athanase & DCI/ Rwandan Defense Force \\
\hline & Chantal Ndikubwimana & IntraHealth/HCSP \\
\hline & Stephanie Marion-Landais & IntraHealth/ HCSP \\
\hline & Mahita Mishra & USAID/ Rwanda \\
\hline \multirow{2}{*}{ Senegal } & Thierno Dieng & CEFOREP \\
\hline & Thiam Sarr Camara & CEFOREP \\
\hline \multirow{14}{*}{ South Africa } & Fiona Nicholson & TVEP \\
\hline & Tapiwa Mukaro & TVEP \\
\hline & Liesl Gerntholz & TLAC \\
\hline & Lisa Vetten & TLAC \\
\hline & Zanele Mophosho & US Department of Defense \\
\hline & Col Pitse & South African Defense Force \\
\hline & Major Irene Thobile & South African Defense Force \\
\hline & Elizabeth Randolph & RTI International \\
\hline & Peter Vaz & RTI International \\
\hline & Latasha Treger & CDC South Africa \\
\hline & Thu-ha Dinh & CDC South Africa \\
\hline & Katherine Liesegang & USAID/SA/DG \\
\hline & Marie McLeod & USAID/SA \\
\hline & Brandon Lawrence & National Prosecuting Authority of SA \\
\hline \multirow{4}{*}{ Uganda } & Major Stephen Kusasira & Uganda Peoples Defense Force \\
\hline & Edward Ssemafumu & NUMAT \\
\hline & Sharon Ajedra & NUMAT \\
\hline & Doris Mwesigire & MJAP \\
\hline Zambia & Mary Zama & Population Council \\
\hline \multirow{2}{*}{ Zimbabwe } & Linda Musiyiwa & Musasa Project \\
\hline & Farirai Mutenherwa & ZNFPC \\
\hline \multirow{10}{*}{$\begin{array}{l}\text { Organizers and } \\
\text { Resource People }\end{array}$} & Ian Askew & Population Council, Nairobi \\
\hline & Jill Keesbury & Population Council, Nairobi \\
\hline & Gladys Mwangi & Population Council, Nairobi \\
\hline & Mantshi Menziwa & Population Council, Johannesburg \\
\hline & Lucy Ng'ang'a & Population Council, Nairobi \\
\hline & Susan Settergren & CDC Atlanta \\
\hline & Peter Iveroth & SIDA \\
\hline & Heidi Mihm & USAID/W \\
\hline & Deborah Cook & USAID/W \\
\hline & Myra Betron & HPI \\
\hline
\end{tabular}




\section{Appendix 2}

\section{AFRICA REGIONAL SGBV NETWORK CONSULTATION Technical Exchange and Planning Meeting With SIDA-Funded Projects \& PEPFAR Initiative Partners \\ March 5 - 7, 2008 \\ Pretoria, South Africa}

\begin{tabular}{|c|c|}
\hline DAY 1 & \\
\hline $9.00-9.45$ a.m. & $\begin{array}{l}\text { Welcome and overview of the SGBV network (Ian Askew, Population Council) } \\
\text { - Overview of the Swedish-Norwegian HIV/AIDS Team in Africa SGBV } \\
\text { Initiative (Peter Iveroth) } \\
\text { - Overview of PEPFAR's SGBV Initiative (Susan Settergren \& Heidi Mihm, } \\
\text { PEPFAR) }\end{array}$ \\
\hline $9: 45-10.15$ a.m. & $\begin{array}{l}\text { PRESENTATIONS BY SIDA PARTNERS (moderator: Gladys Mwangi) } \\
\text { - TLAC } \\
\text { - TVEP }\end{array}$ \\
\hline $10.15-10.30$ a.m. & TE A B R E A K \\
\hline 10.30 a.m. -1.00 p.m. & $\begin{array}{l}- \text { LVCT } \\
\text { - CIMC } \\
\text { DISCUSSIONS ON PRESENTATIONS } \\
\text { - } \text { ESOG } \\
\text { - Malawi } \\
\text { - Musasa } \\
\text { CEFOREP }\end{array}$ \\
\hline $1.00-2.00$ p.m. & L U N C H \\
\hline $2.00-2.30$ p.m. & DISCUSSIONS ON PRESENTATIONS (moderator: Jill Keesbury) \\
\hline $2.30-4.00$ p.m. & $\begin{array}{l}\text { BREAKOUT SESSIONS ON LESSONS LEARNED } \\
\text { - Medical management } \\
\text { - Police and legal services } \\
\text { - Working with communities } \\
\text { - Policy and protocol development }\end{array}$ \\
\hline $4.00-4.30$ p.m. & TE A B R E A K \\
\hline $4.30-5.30$ p.m. & $\begin{array}{l}\text { REPORT BACK ON LESSONS LEARNED FROM KEY THEMATIC AREAS AND } \\
\text { FEEDBACK/DISCUSSIONS (moderator: Ian Askew) }\end{array}$ \\
\hline
\end{tabular}




\begin{tabular}{|c|c|}
\hline DAY 2 & \\
\hline 8.30 a.m. & Recap of Day 1 \\
\hline $9.00-10.30$ a.m. & $\begin{array}{l}\text { PRESENTATIONS BY PEPFAR PARTNERS (moderator: Susan Settergren) } \\
\text { - Rwanda: IntraHealth, Catholic Relief Services, Drew University, } \\
\text { - Columbia University } \\
\text { - Uganda: Uganda Police; NUMAT, MJAP } \\
\text { DISCUSSIONS ON ON PRESENTATIONS }\end{array}$ \\
\hline $10.30-10.45$ a.m. & TE A B R A K \\
\hline $10.45-1.00$ p.m. & $\begin{array}{l}\text { WORK PLANNING BREAKOUT SESSIONS } \\
\text { - } \quad \text { PEPFAR work plans and TA needs (moderators: Jill and Myra) } \\
\text { - } \quad \text { SIDA exchange and TA planning (moderators: Gladys and lan) }\end{array}$ \\
\hline $1.00-2.00$ p.m. & L UN C H \\
\hline $2.00-4.00$ p.m. & WORK PLANNING (continued) \\
\hline $4.00-4.15$ p.m. & TE A B R E A K \\
\hline $4.15-5.30$ p.m. & WORK PLANNING (continued as needed) \\
\hline
\end{tabular}

\begin{tabular}{|c|c|}
\hline DAY 3 & \\
\hline $8.30-9.00$ a.m. & $\begin{array}{l}\text { SUMMARY OF KEY STRATEGIES AND TA NEEDS FROM BREAKOUT GROUPS (Jill } \\
\text { and Gladys) }\end{array}$ \\
\hline $9.00-10.15$ a.m. & $\begin{array}{l}\text { PERSPECTIVES ON DATA UTILIZATION } \\
\text { - How SIDA will use program data (Peter Iveroth) } \\
\text { - How PEPFAR will use program data (Susan Settergren) } \\
\text { DISCUSSION }\end{array}$ \\
\hline $10.15-10.30$ a.m. & TE A B R E A K \\
\hline $10.30-12.00$ a.m. & $\begin{array}{l}\text { PANEL DISCUSSION ON DATA COLLECTION, M \& E STRATEGIES AND } \\
\text { CHALLENGES: } \\
\text { - Members: Population Council, TLAC, TVEP, CMIC, LVCT } \\
\text { (moderators: lan and Jill) }\end{array}$ \\
\hline 12.00 a.m. -1.00 p.m. & $\begin{array}{l}\text { PLENARY DISCUSSIONS AND WRAP-UP (Jill Keesbury) } \\
\text { CLOSING }\end{array}$ \\
\hline 1.00 p.m. & L U N C H \\
\hline
\end{tabular}

